\title{
A fluorometric assay for trehalose in the picomole range
}

Petronia Carillo ${ }^{1 * \dagger}$, Regina Feil ${ }^{2 \dagger}$, Yves Gibon ${ }^{2,3}$, Namiko Satoh-Nagasawa ${ }^{4,5}$, David Jackson ${ }^{4}$, Oliver E Bläsing ${ }^{2,6}$, Mark Stitt ${ }^{2}$ and John Edward Lunn ${ }^{2}$

\begin{abstract}
Background: Trehalose is a non-reducing disaccharide that is used as an osmolyte, transport sugar, carbon reserve and stress protectant in a wide range of organisms. In plants, trehalose 6-phosphate (Tre6P), the intermediate of trehalose biosynthesis, is thought to be a signal of sucrose status. Trehalose itself may play a role in pathogenic and symbiotic plant-microbe interactions, in responses to abiotic stress and in developmental signalling, but its precise functions are unknown. A major obstacle to investigating its function is the technical difficulty of measuring the very low levels of trehalose usually found in plant tissues, as most of the established trehalose assays lack sufficient specificity and/or sensitivity.
\end{abstract}

Results: A kinetic assay for trehalose was established using recombinant Escherichia coli cytoplasmic trehalase (treF), which was shown to be highly specific for trehalose. Hydrolysis of trehalose to glucose is monitored fluorometrically and the trehalose content of the tissue extract is determined from an internal calibration curve. The assay is linear for $0.2-40 \mathrm{pmol}$ trehalose, and recoveries of trehalose were $\geq 88 \%$. A. thaliana Col-0 rosettes contain about 20-30 nmol g ${ }^{-1} \mathrm{FW}$ of trehalose, increasing to about $50-60 \mathrm{nmol} \mathrm{g}{ }^{-1} \mathrm{FW}$ in plants grown at $8^{\circ} \mathrm{C}$. Trehalose is not correlated with sucrose content, whereas a strong correlation between Tre6P and sucrose was confirmed. The trehalose contents of ear inflorescence primordia from the maize ramosa3 mutant and wild type plants were $6.6 \pm 2.6 \mathrm{nmol} \mathrm{g}{ }^{-1} \mathrm{FW}$ and $19.0 \pm 12.7 \mathrm{nmol} \mathrm{g}{ }^{-1} \mathrm{FW}$, respectively. The trehalose:Tre6P ratios in the ramosa3 and wild-type primordia were $2.43 \pm 0.85$ and $6.16 \pm 3.45$, respectively.

Conclusion: The fluorometric assay is highly specific for trehalose and sensitive enough to measure the trehalose content of very small amounts of plant tissue. Chilling induced a 2-fold accumulation of trehalose in A. thaliana rosettes, but the levels were too low to make a substantial quantitative contribution to osmoregulation. Trehalose is unlikely to function as a signal of sucrose status. The abnormal inflorescence branching phenotype of the maize ramosa3 mutant might be linked to a decrease in trehalose levels in the inflorescence primordia or a downward shift in the trehalose:Tre6P ratio.

Keywords: Arabidopsis thaliana, Ramosa3, Trehalase, Trehalose, Zea mays

\section{Background}

Trehalose ( $\alpha$-D-glucopyranosyl-( $1 \rightarrow 1)$ - $\alpha$-D-glucopyranoside) is a non-reducing disaccharide that is used as an osmolyte, storage reserve, transport sugar and stress protectant by many groups of organisms including bacteria, archaea, fungi and invertebrates. For many years it has been known

\footnotetext{
*Correspondence: petronia.carillo@unina2.it

${ }^{\dagger}$ Equal contributors

'Dipartimento di Scienze e Tecnologie Ambientali Biologiche e

Farmaceutiche, Seconda Università degli Studi di Napoli, Via Vivaldi 43,

1-81100, Caserta, Italy

Full list of author information is available at the end of the article
}

that trehalose also occurs in non-vascular plants - algae, mosses and liverworts - and primitive vascular plants [1-4]. Indeed one of the earliest reports of trehalose was from the desiccation-tolerant lycophyte Selaginella lepidophylla [5]. Among the angiosperms, a small number of desiccationtolerant resurrection plants, e.g. Myrothamnus flabellifolia and Sporobolus spp., accumulate considerable amounts of trehalose under drought conditions, reaching up to $20 \%$ of dry weight [6], which may help to maintain cell viability by various mechanisms [7-9]. With the exception of these specialised resurrection plants, it was commonly thought that other flowering plants lacked the capacity to synthesise

\section{Biomed Central}


trehalose, having been displaced by another non-reducing disaccharide - sucrose [10]. The trace amounts of trehalose occasionally reported in some species were generally considered to have a fungal or bacterial origin [11]. This view was completely overturned in 1998 by the unexpected discovery of genes encoding enzymes of trehalose biosynthesis in a desiccation-intolerant model species, Arabidopsis thaliana $[12,13]$.

The most common route for trehalose biosynthesis in prokaryotes, and the only one found in eukaryotes [14], is a two-step pathway involving the synthesis of a phosphorylated intermediate, trehalose-6-phosphate (Tre6P). Tre6P is synthesised from UDPglucose and glucose 6-phosphate by trehalose-phosphate synthase (TPS; EC2.4.1.15) and then the phosphate group is hydrolytically removed by trehalose-phosphate phosphatase (TPP; EC3.1.3.12) to yield free trehalose [15]. Blázquez et al. 1998 [12] reported the discovery of the AtTPS1 gene in A. thaliana, which encodes a catalytically active TPS enzyme, while Vogel et al. 2001 [13] reported the presence of the AtTPPA and $A t T P P B$ genes encoding functional TPPs. Sequencing of the $A$. thaliana genome revealed a total of 11 TPS and 10 TPP genes in this species [16]. Based on yeast mutant complementation and in vitro analysis, AtTPS1 is the only TPS isoform that has been unequivocally shown to have TPS activity, while all ten isoforms of TPP are catalytically active $[17,18]$. The functions of the non-catalytic TPS isoforms (AtTPS2-AtTPS11) remain unclear. Trehalose is catabolised in plants by trehalase (EC3.2.1.28), which in $A$. thaliana is encoded by a single gene (AtTRE1). The enzyme is bound to the plasmalemma with the catalytic site facing the apoplast $[3,19]$. TPS, TPP and TRE genes have subsequently been identified in all major groups of plants, including both monocots and eudicots among the flowering plants, suggesting that the capacity to synthesise and degrade trehalose is universal in the plant kingdom $[14,20]$.

In A. thaliana, tps1 null mutants are non-viable due to arrest of embryo development at the torpedo stage [21]. The tps1 embryos can be rescued by dexamethasoneinducible (GVG::TPS1) or embryo-specific (ABI3::TPS1) expression of TPS1 but, after germination, plants that no longer express the TPS1 gene grow poorly and flower late or not at all [22,23]. While these findings showed that trehalose metabolism is essential for normal growth and development at all stages of the plant's life cycle - embryogenesis, vegetative growth and flowering - they did not reveal its function. Many of the growth and developmental defects in the tps 1 and other mutants with altered trehalose metabolism have been ascribed to changes in Tre6P rather than trehalose itself [24]. Consequently, much current research into plant trehalose metabolism is focussed on understanding the precise functions of Tre6P and the molecular mechanisms underlying its regulation of metabolism, growth and development [25-31]. Tre6P can be measured in the pico/femtomole range by high performance anion-exchange liquid chromatography coupled to tandem mass spectrometry (LC-MS/MS) [32]. It was shown that the level of Tre6P increased up to 40fold when sucrose was supplied exogenously to C-starved A. thaliana seedlings, and that Tre6P also changes in parallel with endogenous changes in the level of sucrose during the diurnal cycle. The strong correlation between sucrose and Tre6P led to the proposal that Tre6P acts as a signal of sucrose status [32].

The evidence that Tre6P has an essential signalling function in plants is compelling, but does not exclude a significant role for trehalose itself. In fact, several studies have implicated trehalose as an important factor in plantmicrobe interactions and in responses to abiotic stresses (reviewed in [33]). Several studies have suggested a role for trehalose in pathogenic plant-microbe interactions. Pseudomonas aeruginosa strain PA14 is a multi-host pathogen that infects nematodes, insects vertebrates and plants. Mutants of $P$. aeruginosa that lack the capacity to synthesise trehalose are unable to infect $A$. thaliana, but unaffected in their ability to infect non-plant hosts, indicating that trehalose is a virulence factor in $P$. aeruginosa that is specific for plant infection [34]. Although its precise role in this plant-pathogen interaction is not yet established, trehalose synthesis appears to be necessary for the bacterium to take up nitrogen-containing nutrients from the plant and to replicate in the extracellular spaces of the plant. Similarly, Magnaporthe grisea, a filamentous fungal pathogen that causes blast disease in rice, requires a functional Tps1 gene in order to infect its host plant [35]. Most A. thaliana accessions are highly susceptible to infection by the clubroot pathogen - Plasmodiophora brassicae - but Burren-0 (Bur-0) shows partial resistance that has been linked to its greater tolerance of pathogeninduced trehalose accumulation [36]. Infection of $A$. thaliana with this pathogen had previously been shown to induce trehalase expression in the plant [37]. Supplying trehalose exogenously to A. thaliana induced a number of pathogen defence related genes, as well as genes linked to abiotic stress responses [38,39], and trehalose application to wheat (Triticum aestivum) induced partial protection against the fungal pathogen Blumeria graminis (powdery mildew) $[40,41]$.

There is evidence that trehalose also plays a role in some beneficial plant-microbe interactions, including rhizobial symbioses in legumes [42-48] and ectomycorrhizal symbioses with tree species [49-51]. The non-symbiotic association of a plant growth-promoting rhizobacterium, Burkholderia phytofirmans, with grapevine led to activation of trehalose metabolism and improved chilling tolerance in the plants [52]. Inoculation of maize with another rhizobacterium, Azospirillum brasiliense, that had been engineered to increase trehalose production, led to a $73 \%$ 
increase in plant biomass, and improved the plants' drought tolerance and grain yield [53].

In addition to the trehalose-accumulating resurrection plants, other species show changes in their trehalose metabolism in response to abiotic stresses. In A. thaliana, the expression of many of the genes associated with trehalose biosynthesis is altered in response to cold, osmotic and salt stresses [54]. In rice, OsTPP1 transcripts were highly induced within a few hours of chilling stress and trehalose levels increased, suggesting a possible role for trehalose in the plants' adaptation to cold [55]. Overexpression of OsTPP1 in transgenic rice plants was found to enhance their tolerance of cold and salt stresses, lending support to this hypothesis [56]. Expression of OsTPP1 (and OsTPP2) was also increased in transgenic rice plants that over-express OsMYBS3, a cold-induced transcription factor that is required for chilling-induced cold tolerance in rice [57]. From these results, it has been suggested that cold-induced changes in OsTPP expression and trehalose content in wild-type plants may be a transient response that helps to protect the plant in the short-term while it adapts to the cold, and may act as a signal for triggering long-term adaptive responses.

Expression of heterologous TPS and TPP genes (from yeast or bacteria) in plants has been reported to improve tolerance to drought, salt, cold and oxidative stresses [58-61]. However, the plants often showed pleiotropic effects, such as changes in leaf shape and senescence, that could be ascribed to changes in the level of Tre6P $[24,62]$. Improvements in abiotic stress tolerance without obvious pleiotropic effects have been reported from: (i) expression of bifunctional TPS-TPP enzymes [63-65]; (ii) targeting of the heterologous enzyme(s) to the chloroplasts [66]; and (iii) expression of TPS and TPP genes under the control of stress-inducible promoters $[67,68]$.

Interestingly, in many of these studies, the levels of trehalose were below the limits of detection of the assay methods employed, not only in the wild-type control plants but also in the stress-tolerant transgenic lines, unless the plants were treated with validamycin A to inhibit the endogenous trehalase $[58,69]$. Therefore, it is doubtful that trehalose made a quantitatively important contribution to osmoregulation in these plants, or exerted protection via mass action effects, unless its distribution was highly localised.

The A. thaliana tre1-1 null mutant has no detectable trehalase activity and accumulates about 4-fold more trehalose than wild-type plants. Surprisingly, despite its higher trehalose content, the tre1-1 mutant was found to be more susceptible to drought stress than the wild-type [70]. Drought stress leads to an increase in abscisic acid (ABA) levels in plants, triggering closure of the stomata and so reducing water loss from the leaves, but this response to ABA was impaired in the tre1-1 mutant. In contrast, in AtTRE1 over-expressing lines, which had less trehalose than wild type plants, the stomata were hypersensitive to $\mathrm{ABA}$ and the plants showed greater drought tolerance than the wild-type [70].

These studies of mutants and transgenic lines have shown that the effects of manipulating trehalose metabolism on abiotic stress tolerance are complex, and probably do not involve trehalose acting as a compatible solute and stress protectant in the classical sense [71]. Together with the transcript profiling studies that showed trehaloseinduced changes in expression of biotic and abiotic stress related genes $[38,39,72,73]$, they point to trehalose acting as a signal molecule.

The possibility that both Tre6P and trehalose have signalling functions in plants complicates phenotypic analysis and interpretation of plants with altered TPS and/or TPP activities. A good example is the maize ramosa3 (ra3) mutant, which has abnormally branched male and female inflorescences. This phenotype was shown to be caused by a lesion in a TPP gene (RAMOSA3) that is expressed in discrete domains subtending the axillary inflorescence meristems [74], although the underlying molecular mechanism is still unresolved [29]. Conceptually, the developmental defect in the mutant could result from an increase in Tre6P or a decrease in trehalose due to lower TPP activity in the affected cells, or a combination of both changes (i.e. a shift in the trehalose:Tre6P ratio). It is also possible that the phenotype is independent of any effect on trehalose metabolism and linked to some non-catalytic property of the RAMOSA3 protein instead. To distinguish between these possibilities, there is an obvious need to measure both Tre6P and trehalose in developing inflorescence primordia from wild type and mutant plants.

As noted above, Tre6P can be measured in the pico/ femtomole range by LC-MS/MS [32], but few of the established trehalose assay methods are sensitive and specific enough to measure trehalose in small amounts of plant tissue. Trehalose has been measured in yeast cells by colorimetric detection using anthrone, but this reagent is not specific enough for use with plant extracts as it gives a strong colour reaction with sucrose $[75,76]$. Paper chromatography and crystallization of trehalose [77] is both time consuming and insensitive, requiring large amounts of plant material and multiple fractionation steps, and was found to be unreliable as a quantitative method [76,78]. Gas liquid chromatography [79] and ${ }^{13} \mathrm{C}$-nuclear magnetic resonance [80] are more quantitative methods, but lack sensitivity and also require expensive equipment. High-performance anionexchange chromatography with pulsed amperometric detection (HPAEC-PAD) offers greater sensitivity, with a detection limit in the range of about 15-300 nmol $[81,82]$. However, this method was shown to be unsuitable for measurement of trehalose in A. thaliana, flax 
(Linum usitatissimum) and sugar beet (Beta vulgaris) extracts, due to coelution of trehalose with other compounds, which were not identified, resulting in a 7 - to 13-fold over-estimation of trehalose [83]. Gas chromatography coupled to detection by mass spectrometry (GC-MS) provides both high sensitivity and specificity $[83,84]$, but requires expensive equipment that is not available in many laboratories and has a relatively low throughput. Enzymatic assays, based on hydrolysis of trehalose by trehalase and quantification of the resulting glucose [85], potentially offer good specificity and high throughput, but the colorimetric or spectrophotometric methods commonly used to measure glucose are usually not sensitive enough for trehalose determination in plant extracts.

Here we describe an enzymatic assay for trehalose that is both highly specific and sensitive enough to measure trehalose in as little as $1 \mathrm{mg}$ fresh weight of plant tissue. The assay is based on specific hydrolysis of trehalose to glucose by recombinant $E$. coli cytoplasmic trehalase (treF), coupled to fluorometric detection of the glucose by glucose oxidase and peroxidase (Figure 1). Using this assay we were able to quantify trehalose in inflorescence primordia from the maize ramosa3 mutant and wild type plants, and compare these with the levels of Tre6P measured by LC-MS/MS in the same extracts. We also investigated whether trehalose, like Tre6P, changes in parallel with sucrose during the diurnal cycle in $A$. thaliana rosettes, and studied the effect of low temperature on the trehalose levels in this species.

\section{Results and discussion}

\section{Substrate specificity of trehalases from porcine kidney} and $E$. coli

Preliminary experiments were carried out using a commercially available porcine kidney trehalase (Sigma-
Aldrich) to test the specificity of this enzyme. Glucose production was determined fluorometrically by coupling the oxidation of glucose to peroxidation of the fluorogenic substrate 10-acetyl-3,7-dihydroxyphenoxazine (Amplex $\operatorname{Red}^{\oplus}$ ), using glucose oxidase and peroxidase (Figure 1B). Reaction mixtures initially contained known amounts of various glucose-containing sugars, the coupling enzymes and Amplex Red ${ }^{\oplus}$. When the baseline fluorescence signal was stable, porcine kidney trehalase was added and the production of glucose was continuously monitored until the reaction was complete. The difference in fluorescence ( $\Delta$ fluorescence) between the baseline and the end point of the reaction was calculated and the results are shown in Figure 2A. The porcine kidney trehalase was found to hydrolyse not only trehalose but also maltose, yielding similar amounts of glucose with both sugars. There was no apparent reaction with sucrose. The maltose content of wild-type $A$. thaliana leaves ranges from about $5 \mathrm{nmol} \mathrm{g}^{-1} \mathrm{FW}$ during the day up to $90 \mathrm{nmol} \mathrm{g}^{-1} \mathrm{FW}$ at night [86,87], and so is similar or higher than the level of trehalose measured by GC-MS in this tissue - about $50 \mathrm{nmol} \mathrm{g}{ }^{-1} \mathrm{DW}$ (equivalent to approximately $5 \mathrm{nmol} \mathrm{g}^{-1} \mathrm{FW}$ ) [83]. Thus the level of maltose in plant extracts is sufficient to seriously interfere with any assay of trehalose content using the porcine kidney trehalase, which does not distinguish between these two sugars. Therefore, we sought an alternative form of trehalase that would be specific for trehalose.

The Escherichia coli cytoplasmic trehalase (treF) was reported to be highly specific for trehalose, showing no hydrolytic activity with maltose, sucrose or lactose [88], suggesting that it might be suitable for enzymatic assay of trehalose in plant tissues. The treF trehalase was overexpressed in E. coli as a $\mathrm{His}_{6}$-tagged fusion protein, and purified to near homogeneity by immobilised metal affinity chromatography, gel filtration and anion-exchange chromatography (see Additional file 1: Figure S1). End
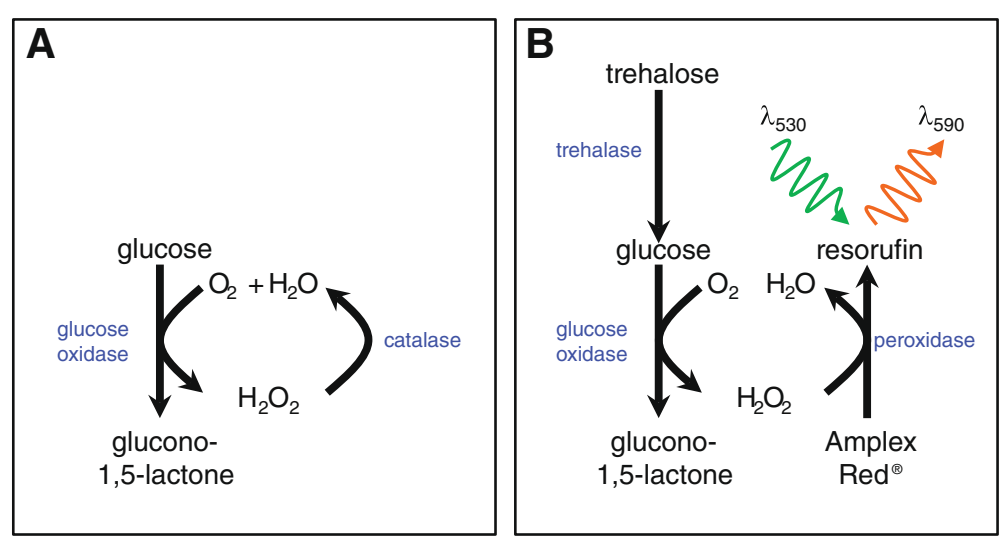

Figure 1 Principle of the fluorometric assay of trehalose. (A) First, glucose is eliminated from the tissue extract by incubation with glucose oxidase and catalase. (B) After inactivation of the glucose oxidase and catalase, trehalose is then hydrolysed to glucose by trehalase. Glucose is determined by coupling to peroxidation of a fluorogenic substrate, Amplex Red ${ }^{\oplus}$, using glucose oxidase and peroxidase and measuring the increase in fluorescence at $590 \mathrm{~nm}$. 

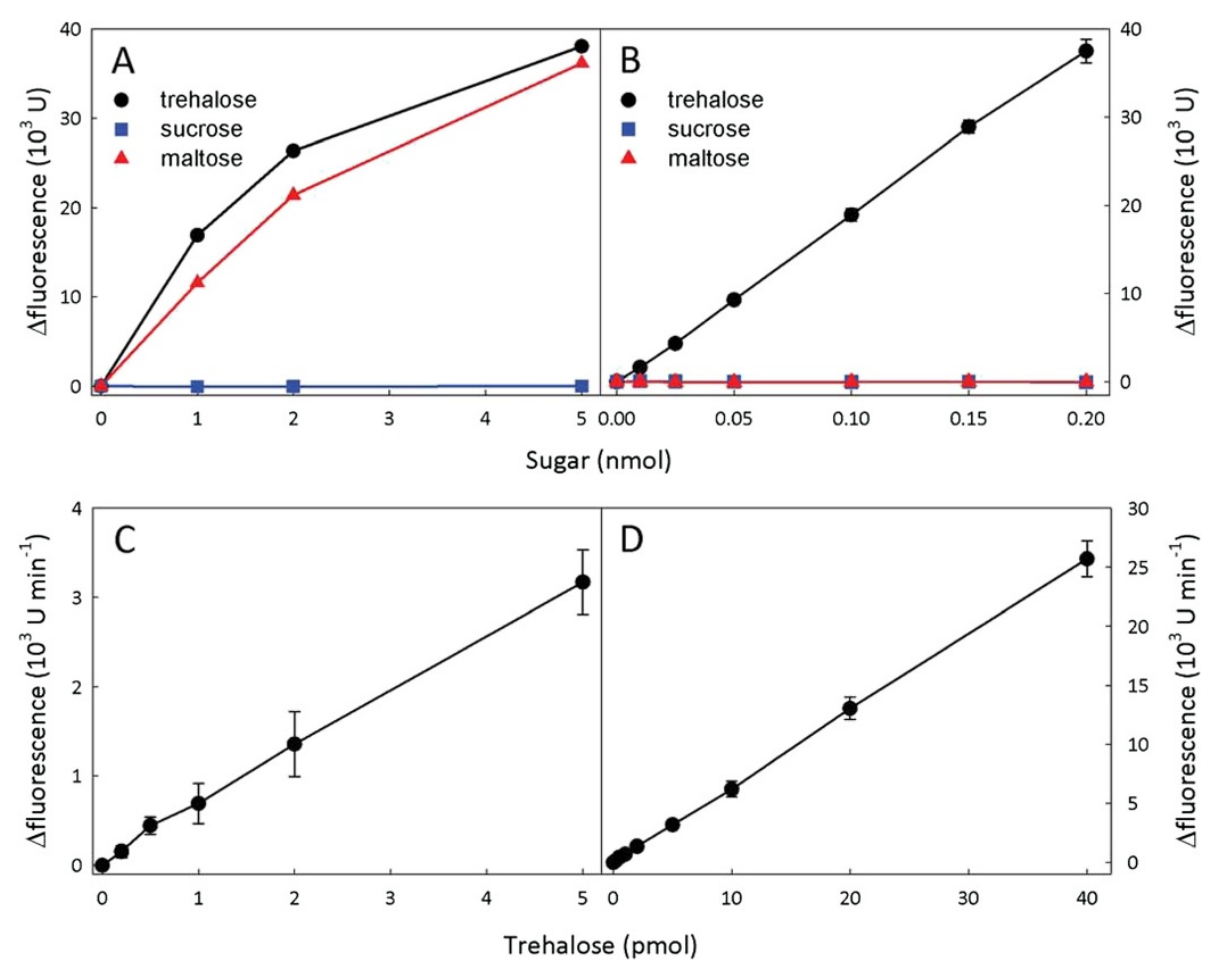

Figure 2 Specificity of different trehalases and linearity of the fluorometric assay of trehalose. Hydrolysis of trehalose and other disaccharides by (A) porcine kidney trehalase and (B) E. coli cytoplasmic trehalase (treF). The amount of glucose released after addition of trehalase was determined in an end-point assay using glucose oxidase, peroxidase and Amplex Red ${ }^{\oplus}$. The increase in fluorescence is expressed in arbitrary fluorescence units. The linearity of the optimised kinetic assay for trehalose using $E$. coli cytoplasmic trehalase was tested with $0-5$ pmol trehalose $(\mathbf{C})$ and $0-40 \mathrm{pmol}$ trehalose (D). The initial rate of the reaction was monitored fluorometrically (arbitrary fluorescence units min ${ }^{-1}$ ). Data are mean $\pm \mathrm{SD}(n=2$ or 3$)$.

point assays with glucose-containing oligosaccharides that are likely to be present in plant extracts confirmed that the treF enzyme has no significant hydrolytic activity with maltose, sucrose, maltotriose or cellobiose (Figure 2B and Additional file 2: Figure S2). The amount of glucose released from trehalose was directly proportional to the amount of trehalose in the assay (Figure 2B). Based on these results, the treF trehalase was judged to be suitable for determination of trehalose in plant extracts.

\section{Optimisation and validation of a kinetic assay for trehalose}

Plant tissues usually contain substantial amounts of glucose, for example, $A$. thaliana leaves typically have around 0.5-5 $\mu \mathrm{mol} \mathrm{g} \mathrm{g}^{-1} \mathrm{FW}$ [89]. This will obviously interfere with any trehalose assay based on measurement of the glucose, unless the original glucose in the extract is first removed. This can be achieved by incubating the tissue extract with glucose oxidase and catalase to bring about quantitative oxidation of glucose to gluconate. The destruction of the reaction by-product, hydrogen peroxide, by catalase regenerates the oxygen needed for oxidation of glucose and drives the reaction to completion (Figure 1A). After removal of glucose, the enzymes are inactivated by heating. Trehalose can then be determined by addition of trehalase and measurement of glucose production using glucose oxidase, peroxidase and Amplex $\operatorname{Red}^{\oplus}$ (Figure 1B). With trehalose standards, the end-point assay described in the previous section was shown to give a linear response for $10-200 \mathrm{nmol}$ of trehalose (Figure 2B). As it was desirable to measure trehalose in the same extracts as those used for measurement of Tre6P by LC-MS/MS, the following experiments were performed using chloroform-methanol extracts prepared as described in [32]. Initial trials with extracts from various $A$. thaliana tissues indicated the end-point method was sensitive enough to measure trehalose in flowers, which have relatively high levels of trehalose $\left(218 \pm 47 \mathrm{nmol} \mathrm{g}^{-1} \mathrm{FW}\right)$, but the levels of trehalose in leaves $\left(28 \pm 6 \mathrm{nmol} \mathrm{g}^{-1} \mathrm{FW}\right)$ and roots $\left(25 \pm 5 \mathrm{nmol} \mathrm{g}^{-1} \mathrm{FW}\right)$ were much lower and close to the limit of detection of the endpoint assay. Therefore, a potentially more sensitive kinetic assay was tested.

The kinetic assay is based on measurement of initial rates of trehalase activity with sub-saturating amounts of trehalose, below the $K_{m}(1.9 \mathrm{mM})$ of the $E$. coli treF trehalase [88], and limiting amounts of trehalase in the assay. Under such conditions, the activity of the enzyme 
is essentially linear with respect to the concentration of trehalose. To calibrate the assay, it is necessary to generate an internal standard curve for each sample. This is done by addition of known amounts of trehalose (or water for the blank) to equal aliquots of the tissue extract, from which all traces of trehalose and glucose have previously been removed by prior incubation with trehalase (treF), glucose oxidase and catalase. An equivalent aliquot of the extract is incubated with glucose oxidase and catalase to remove only glucose. Trehalose is then assayed in all of the aliquots in parallel by addition of a limiting amount of treF trehalase, along with glucose oxidase, peroxidase and Amplex $\operatorname{Red}^{\oplus}$. The initial rate of each reaction is monitored fluorometrically. The slope of the linear portion of each reaction is calculated and the blank rate is subtracted. The amount of trehalose in the original extract is determined by comparing the rate of the reaction for the aliquot that was not pre-incubated with trehalase with the rates of the reactions spiked with known amounts of trehalose. All reactions were carried out (in duplicate) in 96-well microplates, allowing several samples to be analysed simultaneously. Measurements were done on a microplate reader operating in fluorescence mode, using an excitation wavelength of $530 \mathrm{~nm}$ and detection of emission at $590 \mathrm{~nm}$. Depending on the expected amount of trehalose in the extract, a low $(0.2-4 \mathrm{pmol})$ or high (2-20 pmol) range of trehalose standards was used for the internal calibration curve. Calibration plots were highly linear up to $40 \mathrm{pmol}$ of trehalose (Figure $2 \mathrm{C}$ $\mathrm{D})$, although the slope can vary considerably between tissue types, presumably due to differences in the degree of quenching by other compounds in the extract. However, the use of an internal calibration curve for each sample automatically compensates for any variation in quenching or background fluorescence from components of the plant extract.

We also compared the sensitivity and linearity of the assay using Amplex $\operatorname{Red}^{\oplus}$ and an alternative formulation of the fluorogenic substrate, Amplex UltraRed ${ }^{\circledR}$ (Invitrogen), which is claimed by the manufacturer to give a higher fluorescence yield. In trials with trehalose standards and $A$. thaliana leaf extracts, Amplex UltraRed ${ }^{\circledR}$ gave a marginally higher fluorescence signal than with Amplex $\operatorname{Red}^{\oplus}$, but slightly higher blanks (data not shown). Therefore, there appeared to be no great advantage in using Amplex UltraRed ${ }^{\oplus}$, and the original Amplex $\operatorname{Red}^{\circledR}$ reagent was used in most of the subsequent analyses.

Experiments were carried out to determine the recovery of trehalose from extraction of $A$. thaliana leaf samples with chloroform-methanol. Quadruplicate aliquots of frozen tissue powder (12-15 mg FW, containing 270-580 pmol of trehalose) were spiked with either 500 or 1500 pmol of trehalose before extraction. Spiked and non-spiked control samples were extracted with chloroform-methanol [32], and trehalose was measured in $5 \mu \mathrm{l}$ of the extract (total extract volume $250 \mu \mathrm{l}$ ). The non spiked samples contained $30.3 \pm 7.5 \mathrm{nmol} \mathrm{g}^{-1} \mathrm{FW}$ of trehalose (mean $\pm \mathrm{SD}, n=4$ ). From the amounts of trehalose measured in the spiked samples, the recoveries of the added 500 and 1500 pmol of trehalose were calculated to be $98 \pm 22 \%$ and $92 \pm 16 \%$, respectively. In a similar experiment using Amplex UltraRed ${ }^{\circledR}$ reagent, non-spiked samples contained $32.8 \pm 6.0 \mathrm{nmol} \mathrm{g}{ }^{-1} \mathrm{FW}$ (mean $\pm \mathrm{SD}, n=4$ ), and the recoveries of 500 and 1500 pmol of trehalose were $105 \pm 10 \%$ and $88 \pm 4 \%$, respectively. These experiments demonstrated the reliability of the chloroform-methanol extraction method for quantitative recovery of trehalose, and that there was no significant loss of trehalose during the initial incubation with glucose oxidase/catalase to remove glucose.

\section{Diurnal changes in the trehalose content of $A$. thaliana leaves and its response to low temperature}

The amount of Tre6P in A. thaliana seedlings and soilgrown plants was found to be correlated with the level of sucrose [32]. As Tre6P is the direct precursor of trehalose, it might be expected that trehalose also changes in response to diurnal fluctuations in sucrose. To investigate this possibility, trehalose, Tre6P and sucrose were measured in rosettes of wild type A. thaliana Col-0 plants grown at $20^{\circ} \mathrm{C}$ and harvested at 4-h intervals through a $12 \mathrm{~h}$ light/12 h dark diurnal cycle. All three metabolites showed a moderate increase during the day, before falling back down at night (Figure 3A-C).

The starch-deficient plastidial phosphoglucomutase (pgm) mutant shows more pronounced diurnal changes in sugars, therefore, we carried out a similar analysis of pgm plants grown under the same conditions. The pgm plants accumulated about 3-fold higher levels of sucrose by the end of the day (Figure 3D) than wild-type Col-0 plants. There was a sharp drop in sucrose levels by $4 \mathrm{~h}$ into the night, and sucrose decreased even further by the end of the night, falling below the levels seen in the wild-type plants (Figure 3A). These marked changes in sucrose content were closely paralleled by a large diurnal fluctuation in the level of Tre6P in the pgm plants (Figure 3E). In contrast, trehalose levels remained almost constant throughout the light-dark cycle (Figure 3F), and were slightly lower than those seen in the wild-type Col-0 plants (Figure 3C).

Plants exposed to low temperatures often accumulate substantial amounts of sucrose and other sugars [90]. Therefore, it was of interest to determine whether low temperatures affect the level of trehalose in A. thaliana. Wild type plants were grown in a $12 \mathrm{~h} / 12 \mathrm{~h}$ light-dark cycle as above for 3 weeks and then exposed to a chilling temperature of $8^{\circ} \mathrm{C}$ for 1 week. These plants contained about 6-10 times higher levels of sucrose throughout 


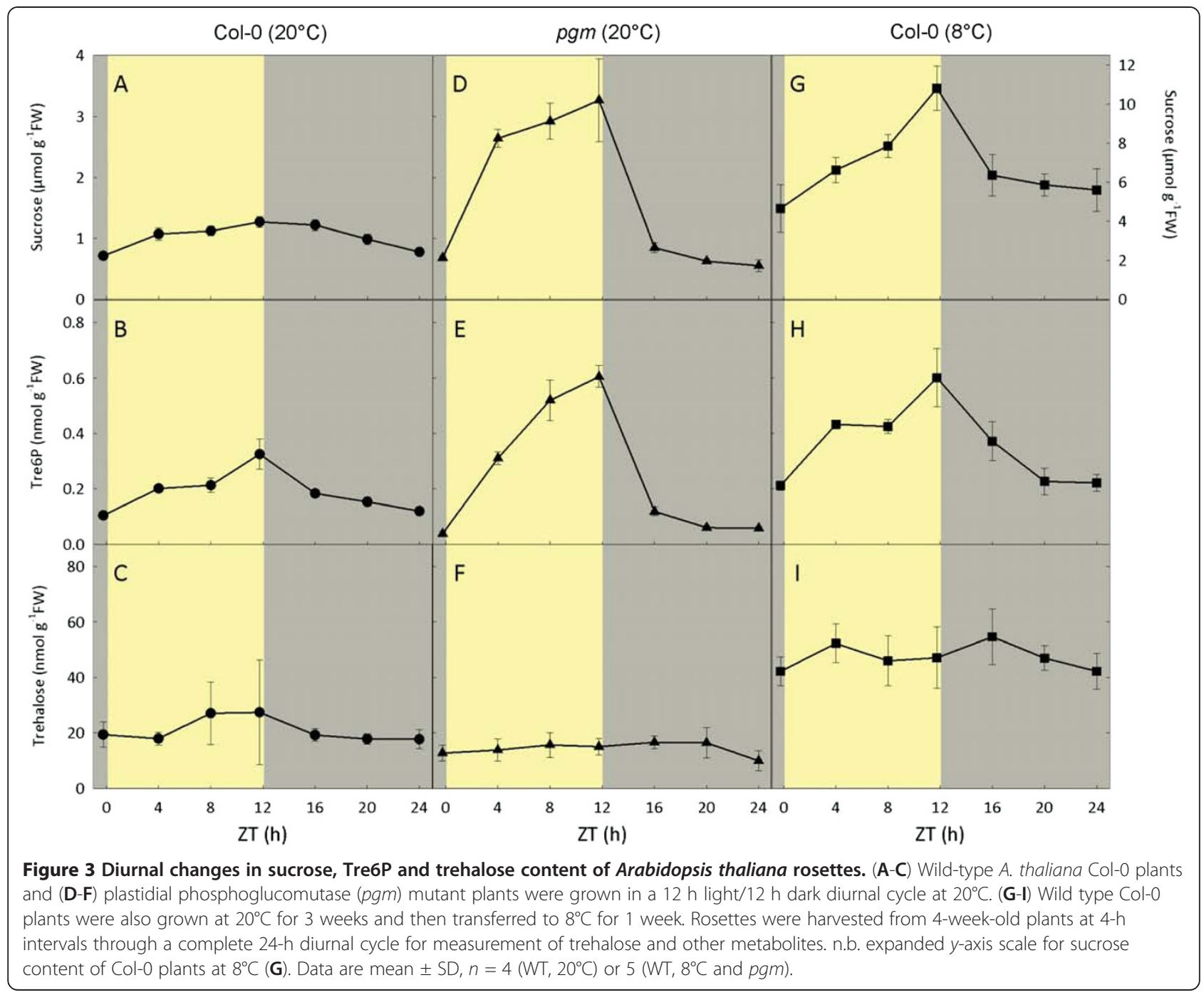

the diurnal cycle than those grown at $20^{\circ} \mathrm{C}$, peaking at the end of the day and then falling at night (Figure 3G). As seen in the other plants, Tre6P showed a similar diurnal rhythm to sucrose, but the levels were about 2-fold higher than those seen in non-chilled wild-type plants (Figure $3 \mathrm{H}$ ). Trehalose was about 2.5-fold higher in the cold-treated plants than those grown at $20^{\circ} \mathrm{C}$, but again showed only minor fluctuations during the diurnal cycle (Figure 3I).

To quantify the relationships between sucrose, trehalose and Tre6P, pairwise comparisons of metabolite levels were plotted (using data from the individual samples), and the Pearson's correlation coefficient $(r)$ calculated for each pair of metabolites in the three experiments (Figure 4). In all three sets of plants, Tre6P was strongly correlated with sucrose, with r-values ranging from $0.787\left(\mathrm{Col}-0\right.$ at $\left.8^{\circ} \mathrm{C}\right)$ to $0.938\left(\mathrm{pgm}\right.$ at $\left.20^{\circ} \mathrm{C}\right)$, and the correlations were highly significant, with $P$ values ranging from $1.5 \times 10^{-7}$ to $9.1 \times 10^{-17}$ (Figure $4 \mathrm{~A}-\mathrm{C}$ ). In contrast, there was no significant correlation between trehalose and sucrose (Figure 4D-F). Trehalose was weakly correlated with Tre6P in both sets of wild-type Col-0 plants $(P<0.05)$, but not in the pgm plants (Figure 4G-I).

These results confirm the strong relationship between sucrose and Tre6P that has previously been observed in various $A$. thaliana tissues [31,32], lending weight to the hypothesis that Tre6P acts as a signal of sucrose status in plants. Interestingly, although Tre6P was highly correlated with sucrose in all three sets of plants, the slope of the regression plot was substantially lower for the coldtreated wild-type Col-0 plants (0.054) than those grown at $20^{\circ} \mathrm{C}(0.277)$, or the pgm plants $(0.178)$. This suggests that while the strong relationship between these metabolites is maintained at low temperature, it is poised at a lower Tre6P:sucrose ratio. This may allow the plants to remain responsive to fluctuations in the level of sucrose even though the absolute amounts of sucrose are much higher than in non-chilled plants. The high concentrations 


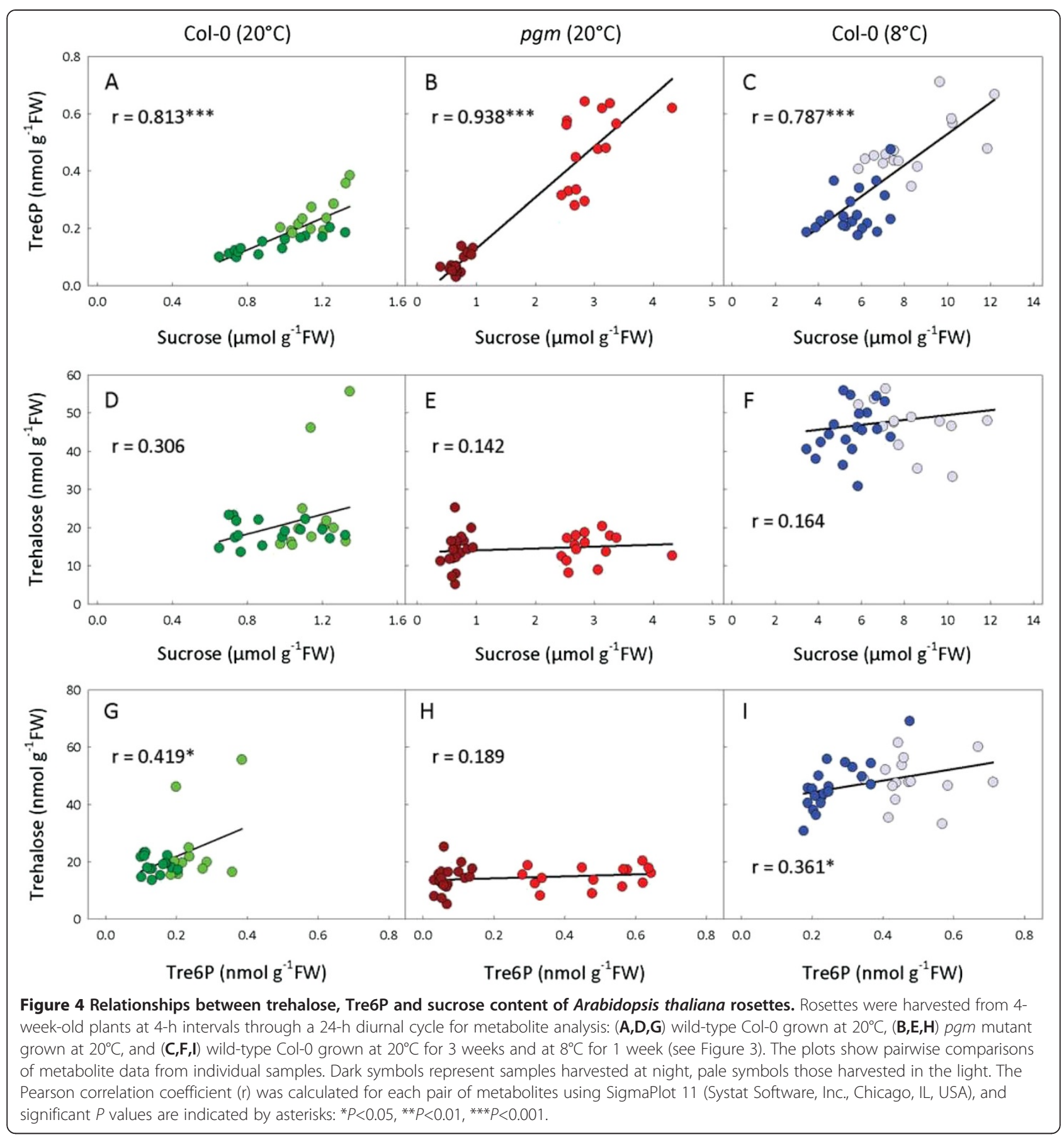

of sucrose in the cells will at least partially offset the thermodynamic decrease in maximal catalytic activities of the enzymes at low temperature, and so help to maintain metabolic fluxes under these conditions. Sucrose accumulation may also be part of the plant's acclimatory response, offering some protection against anticipated freezing temperatures. Even though the low-temperature treated plants had moderately elevated trehalose levels (about 2.5 times higher than at $20^{\circ} \mathrm{C}$ ), it is worth noting that the absolute amounts of sucrose were over 200 -fold higher than those of trehalose. Thus trehalose does not appear to make a substantial quantitative contribution to osmoregulation under these conditions, and any direct protective effect seems doubtful. These results are consistent with the increased but still low absolute amounts of trehalose found in rice and grapevine after chilling $[52,55]$.

The absence of any obvious correlation between sucrose and trehalose (Figure 4D-F) argues against trehalose having a similar sucrose-signalling function to Tre6P. The relationship between Tre6P and trehalose was surprisingly 
weak, with no significant correlation at all in the $p g m$ mutant (Figure 4G-I). The level of trehalose in the plants is presumably governed by: (i) the supply of Tre6P, (ii) the activity of TPP, and (iii) the activity of trehalase. Although experimental data are sparse, it is likely that Tre6P and trehalose are produced mainly in the cytosol [91], whereas the trehalase enzyme has been shown to be anchored in the plasmalemma with the active site facing the apoplast $[3,19]$. Presumably there must be some kind of transport mechanism for exporting trehalose out of the cell to make it accessible to the trehalase. Although nothing is known about how this is brought about, the transport of trehalose out of the cell could be an additional control point for regulating the level of trehalose. These uncertainties highlight the substantial gaps in our knowledge about the subcellular compartmentation of trehalose metabolism in plant cells.

\section{Metabolite analysis of inflorescence primordia from wild- type and ramosa 3 maize plants}

Previous attempts to measure Tre6P and trehalose in developing inflorescence primordia from the maize ramosa3 mutant had been unsuccessful, leaving open the question of whether the loss of the RAMOSA3 TPP activity affected either or both of these metabolites [74]. The fluorometric assay we have established is not only sensitive enough to measure trehalose in very small amounts of plant tissue (as little as $1 \mathrm{mg}$ ), but also has the advantage that Tre6P can be measured in the same extracts by LC-MS/MS [32]. This opened up the possibility to measure both of these metabolites in ramosa 3 inflorescence primordia.

Ear inflorescence primordia were harvested from wildtype (B73) and ramosa3 maize plants grown in the field, at the 1-4 mm stage when the RAMOSA3 gene is expressed (from 9 to 10-week-old plants). There appeared to be a tendency for the ramosa 3 primordia to have lower trehalose than those from wild-type plants (Figure 5A), but the large biological variation between samples, particularly those from the wild-type plants, rendered the difference non-significant according to Student's $t$-test $(P=0.106)$. There was no difference in Tre6P levels between wild type and mutant primordia (Figure 5B). It is worth noting that the absolute levels of Tre6P (2.7-2.9 nmol g-1 FW) are at least 5-fold higher than those in A. thaliana leaves (Figure 3D-F), which may reflect the more densely cytoplasmic nature of the cells from developing primordia compared to the highly vacuolated leaf mesophyll cells. Interestingly, however, trehalose levels were not higher on a fresh weight basis than those found in A. thaliana rosettes (Figures 3 and 5).

When analysing such small amounts of tissue, the measurement of the sample fresh weight is likely to be a significant source of experimental error. The ratio of
trehalose:Tre6P in a given sample is independent of the weight, and so might be a more robust parameter for comparison of mutant and wild-type primordia. The trehalose:Tre6P ratio was calculated for the individual samples and the results are shown in Figure 5C. As observed for the absolute amounts of trehalose, the trehalose: Tre6P ratio showed a strong tendency to be lower in the ramosa 3 primordia than in the wild-type but the difference was not statistically significant $(P=0.08)$, although closer to the 0.05 threshold of significance.

It should be noted that the RAMOSA3 gene is expressed in only a minority of the cells in the inflorescence primordia, even at the peak in its expression level [74]. Therefore, even large changes in trehalose and/or Tre6P levels in the RAMOSA3-expressing cells might be partially masked by the pools of these metabolites in the promordia extracts that are derived from cells that do not express RAMOSA3. Nevertheless, based on these results, we tentatively conclude that the abnormal branching phenotype of the ramosa 3 inflorescences is not linked to a change in the level of Tre6P in the primordia. The tendency for trehalose to be decreased in the ramosa 3 primordia would seem to be consistent with a loss or reduction in total TPP activity in the affected cells. However, further experiments will be needed to determine if this tendency is mechanistically linked to the aberrant development of the inflorescences. For example, it would be interesting to test whether the mutant can be complemented by a catalytically incapacitated form of the RAMOSA3 TPP. If the mutant is complemented by such a protein, this would suggest that the developmental phenotype is linked to some other property of the RAMOSA3 protein and its TPP activity is coincidental. If the mutant is not complemented, this would suggest that the phenotype really is linked to disruption of trehalose metabolism in the affected cells.

\section{Conclusions}

We have developed and validated a highly specific and sensitive fluorometric assay for trehalose. The level of trehalose in A. thaliana rosettes showed no obvious dependence on sucrose content. Therefore, trehalose is unlikely to be involved in sucrose signalling pathways, whereas its precursor, Tre6P, was confirmed to be highly correlated with sucrose, supporting its proposed function as a sucrose signal. Trehalose is weakly correlated with Tre6P but only in wild-type Col-0 plants. Trehalose was moderately elevated in $A$. thaliana Col- 0 plants exposed to low temperature $\left(8^{\circ} \mathrm{C}\right)$, compared to non-chilled plants $\left(20^{\circ} \mathrm{C}\right)$. However, the absolute levels of trehalose were still very low, being several orders of magnitude less than sucrose, and so insufficient to make a quantitatively important contribution to osmoregulation. Ear inflorescence primordia from the maize ramosa 3 mutant contained similar 


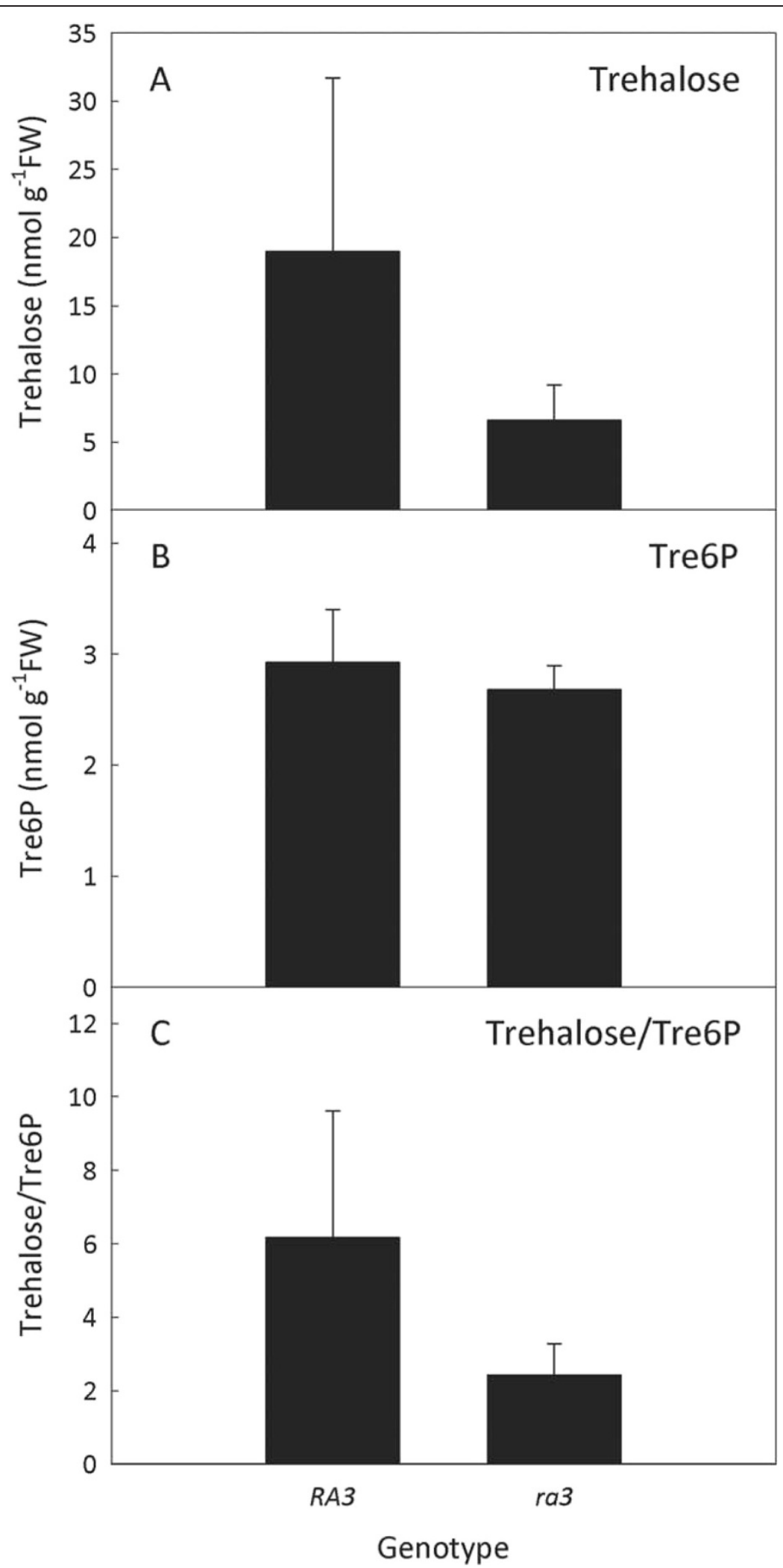

Figure 5 (See legend on next page.) 
(See figure on previous page.)

Figure 5 Trehalose and Tre6P content in maize ramosa3 inflorescence primordia. Ear inflorescence primordia (1-4 mm in length) were harvested from 9 to 10-week-old plants of the ramosa3 (ra3) mutant and wild type B73 (RA3) maize plants. Trehalose (A) was measured fluorometrically and Tre6P (B) was measured by LC-MS/MS. The trehalose:Tre6P ratio (C) was calculated for each individual sample. Data are mean \pm SD $(n=4)$.

levels of Tre6P to primordia from wild-type plants, indicating that the abnormal branching phenotype of the mutant inflorescences is probably not linked to changes in Tre6P content in the affected primordia cells. There was a tendency for trehalose and the trehalose:Tre6P ratio to be lower in the mutant compared to wild-type, but the differences were not statistically significant. This leaves open the question of whether the phenotype is linked to disturbance of trehalose metabolism or to some non-catalytic function of the RAMOSA3 protein. Although the function of the RAMOSA3 protein could not be clearly resolved from the metabolite data, the fact that we were able to measure both trehalose and Tre6P in such small amounts of tissue, where previous attempts had failed, demonstrates the potential of the newly established assay method to advance our understanding of trehalose metabolism and its functions in plants.

\section{Methods}

\section{Plant material}

Arabidopsis thaliana (L.) Heynh. accession Col-0 wild type and pgm mutant [92] plants were grown in soil with a $12 \mathrm{~h}$ light/12 h dark diurnal cycle, an irradiance of 130$160 \mu \mathrm{E} \mathrm{m} \mathrm{m}^{-2} \mathrm{~s}^{-1}$ and a constant temperature of $20^{\circ} \mathrm{C}$, unless stated otherwise. Rosettes were harvested from 25-day-old plants and immediately frozen in liquid nitrogen under ambient irradiance. The frozen plant tissue was ground to a fine powder at liquid nitrogen temperature using a ball mill and stored at $-80^{\circ} \mathrm{C}$ until analysis. Maize (Zea mays) cv. B73 (wild type) and ramosa 3 mutant plants that had been introgressed about six times into B73 [74] were grown in the field at the Cold Spring Harbor Laboratory field station, NY, USA, in May-August 2007. Ear inflorescence primordia (1-4 $\mathrm{mm}$ in length) were rapidly dissected from 9 to 10 -week-old plants in the field and immediately frozen in liquid nitrogen.

\section{Reagents}

Recombinant glucose oxidase from Aspergillus niger (specific acivity $\geq 167 \mathrm{U} \mathrm{mg}^{-1}$ protein, containing $\leq 10 \mathrm{U} \mathrm{mg}^{-1}$ protein of catalase) was obtained from Sigma-Aldrich (Taufkirchen, Germany). Peroxidase from horseradish (Grade I; $250 \mathrm{U} \mathrm{mg}^{-1}$ lyophilisate, containing $<0.7 \%$ catalase) was obtained from Roche (Mannheim, Germany). Porcine kidney trehalase $\left(\geq 1.0 \mathrm{U} \mathrm{mg}^{-1}\right.$ protein) was obtained from Sigma-Aldrich. Amplex $\operatorname{Red}^{\circledR}$ (10-acetyl3,7-dihydroxyphenoxazine) and Amplex RedUltra ${ }^{\circ}$ were purchased from Molecular Probes Europe (Leiden, The Netherlands).

\section{Expression and purification of recombinant E. coli treF trehalase}

The E. coli treF coding region encoding cytoplasmic trehalase (EC 3.2.1.28) was amplified from E. coli genomic DNA by PCR and cloned between the NcoI and EcoRI sites of expression plasmid pETM11. The treF protein was expressed as an $\mathrm{N}$-terminal $\mathrm{His}_{6}$-tagged fusion protein in E. coli strain Rosetta ${ }^{\mathrm{TM}}$ (EMD Millipore, Billerica, MA, USA). Protein expression was induced at a cell density of approx. $4 \times 10^{8}$ cells $\mathrm{mL}^{-1}\left(\mathrm{OD}_{600}=0.5\right)$ with $0.5 \mathrm{mM}$ isopropyl $\beta$-D-thiogalactoside. The induced cells were incubated at $20^{\circ} \mathrm{C}$ for $16 \mathrm{~h}$, harvested by centrifugation at $5000 \times g\left(4^{\circ} \mathrm{C}\right)$ for $10 \mathrm{~min}$, suspended in extraction buffer (50 mM Hepes- $\mathrm{Na}^{+}, 300 \mathrm{mM} \mathrm{NaCl}, \mathrm{pH} 7.5$,) containing $1 \mathrm{mM}$ phenylmethylsulfonyl fluoride, and extracted by single passage through an EmulsiFlex ${ }^{-} \mathrm{C} 3$ high pressure homogenizer (Avestin Inc., Ottawa, Canada) at 110-120 $\mathrm{MPa}$ peak pressure. The cell lysate was clarified by centrifugation at $20,000 \times g\left(4^{\circ} \mathrm{C}\right)$ for $10 \mathrm{~min}$, and the supernatant comprised the soluble extract. All subsequent procedures were carried out at $4^{\circ} \mathrm{C}$. The $\mathrm{His}_{6}$-treF protein was purified by immobilized metal affinity chromatography on Talon ${ }^{\mathrm{Tm}} \mathrm{Co}^{2+}$ resin (Clontech Laboratories, Inc., Mountain View, CA, U.S.A.) according to the manufacturer's instructions. The enzyme was further purified by size-exclusion chromatography on a HiLoad16/60 Superdex 200 column (Amersham Biosciences Europe $\mathrm{GmbH}$, Freiburg, Germany), equilibrated with $50 \mathrm{mM}$ Hepes- $\mathrm{Na}^{+}, 5 \mathrm{mM} \mathrm{MgCl} 2,0.5 \mathrm{mM}$ EDTA, pH 7.5. The

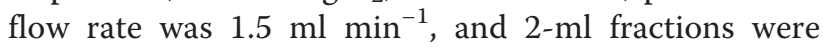
collected. Fractions from the major protein peak were pooled and applied to an HR 5/5 MonoQ ${ }^{\circ}$ anionexchange column (Amersham Biosciences), equilibrated with $50 \mathrm{mM}$ Hepes- $\mathrm{Na}^{+}, 5 \mathrm{mM} \mathrm{MgCl}_{2}, 0.5 \mathrm{mM}$ EDTA, $\mathrm{pH}$ 7.5. $\mathrm{His}_{6}$-treF was eluted with a linear gradient of $0-0.5 \mathrm{M} \mathrm{NaCl}(30 \mathrm{ml})$ in the same buffer. The flow rate was $1 \mathrm{ml} \mathrm{min}{ }^{-1}$ and $0.5-\mathrm{ml}$ fractions were collected. Aliquots $(2 \mu \mathrm{l})$ of the major protein peak fractions were analysed by SDS-polyacrylamide gel electrophoresis on a $10 \%$ polyacrylamide gel stained with Coomassie Blue R-250. Fractions containing a single $67-\mathrm{kDa}$ protein band were pooled and concentrated to a volume of approx. 200 $\mu \mathrm{l}$ using a Centricon Plus-20 (30 kDa cut-off) centrifugal concentrator (EMD Millipore). The purified $\mathrm{His}_{6}$-treF had a specific activity of $80 \mu \mathrm{mol} \mathrm{min} \mathrm{mg}^{-1}$ protein 
(1333 nkat $\mathrm{mg}^{-1}$ protein). The enzyme was stored in the MonoQ column elution buffer at $-80^{\circ} \mathrm{C}$ and was stable for at least 2 years.

\section{Trehalose determination}

Trehalose was extracted from frozen plant tissue using chloroform-methanol as described in Lunn et al. 2006 [32]. The trehalose content of plant extracts was determined using a kinetic assay, measuring trehalase activity in the presence of limiting concentrations of trehalose. Trehalase activity was monitored fluorometrically by coupling with glucose oxidase and peroxidase. Six aliquots $(5 \mu \mathrm{l})$ of the tissue extract (each corresponding to approx. $50 \mu \mathrm{g} \mathrm{FW}$ of tissue) were placed in separate wells of a Costar ${ }^{\circ}$ black polystyrene 96-well microplate (Corning Incorporated, NY, USA) - one aliquot for trehalose determination and the other five for generation of an internal calibration curve including a blank. A reaction mixture $(35 \mu \mathrm{l})$ containing: $4 \mu \mathrm{l}$ of $10 \times$ reaction buffer $\left(500 \mathrm{mM} \mathrm{KH_{2 }} \mathrm{PO}_{4}-\mathrm{KOH}, 10 \mathrm{mM} \mathrm{MgCl} 2,100 \mathrm{mM}\right.$ $\mathrm{NaCl}, \mathrm{pH} 7.5), 100$ nkat catalase and 67 nkat glucose oxidase was added to each aliquot. Five of the reaction mixtures were supplemented with 0.27 nkat trehalase (treF). The microplate was loosely covered and incubated at $30^{\circ} \mathrm{C}$ with constant shaking for $60 \mathrm{~min}$ to remove glucose, or to remove both glucose and trehalose in the five reactions containing trehalase. The microplate was sealed with adhesive foil and heated at $80^{\circ} \mathrm{C}$ for 15 min to inactivate the enzymes. After cooling, the plate was centrifuged at $1000 \times g$ for $1 \mathrm{~min}$ and placed on ice.

Water $(5 \mu \mathrm{l})$ was added to the aliquot that had been incubated without trehalase. To generate an internal calibration curve, $5 \mu \mathrm{l}$ of water were also added to one of the five trehalase-treated samples as a blank, and the remaining four trehalase-treated aliquots were supplemented with $5 \mu \mathrm{l}$ of standard solutions containing 0.04-0.8 $\mu \mathrm{M}$ trehalose (i.e. $1-4 \mathrm{pmol}$ ) or $5 \mu \mathrm{l}$ of $1.0-4.0 \mu \mathrm{M}$ trehalose (i.e. $5-20 \mathrm{pmol}$ ). To each of the six wells was then added $55 \mu \mathrm{l}$ of a reaction mixture containing: $6 \mu$ of $10 \times$ reaction buffer, 0.27 nkat trehalase (treF), 33 nkat glucose oxidase, 0.83 nkat horseradish peroxidase and $0.25 \mu \mathrm{l}$ of $20 \mathrm{mM} 10$-acetyl-3,7dihydroxyphenoxazine (Amplex Red ${ }^{\circ}$; dissolved in DMSO). After mixing, and centrifugation at $1000 \times g$ for $1 \mathrm{~min}$, the resulting trehalase reaction was monitored using a Synergy ${ }^{\circ}$ HT microplate reader (BioTek, Winooski, VT, USA) in fluorescence mode (excitation $530 \mathrm{~nm}$, emission 590) at $25^{\circ} \mathrm{C}$ for $30-40 \mathrm{~min}$. The rate of each reaction was calculated using $\mathrm{Gen}^{\circ}$ software (BioTek). The blank rate was subtracted from all measurements. An internal calibration curve was constructed from the rates of the reactions that had been supplemented with trehalose standards, and used to calculate the trehalose content of the nonsupplemented sample.

\section{Sucrose and Tre6P determination}

Sucrose was measured enzymatically in ethanolic extracts according to [93]. Tre6P was measured in chloroformmethanol extracts by high performance anion exchange liquid chromatography coupled to tandem mass spectrometry (LC-MS/MS) as described in Lunn et al. 2006 [32].

\section{Additional files}

\begin{abstract}
Additional file 1: Figure S1. Purification of the Escherichia coli cytoplasmic trehalase (treF). TreF was over-expressed in E. coli as a $\mathrm{His}_{6}$-tagged fusion protein and purified by immobilised metal affinity chromatography $\left(\mathrm{Co}^{2+}\right.$, Talon $\left.^{\mathrm{TM}}\right)$, size exclusion chromatography (Superdex S200) and anion exchange chromatography (Mono Q). Proteins in 0.5-2 $\mu \mathrm{l}$ aliquots of fractions from each stage of the purification were analysed by SDS polyacrylamide gel electrophoresis (10\% gel) and stained with Coomassie Blue R250. $\mathrm{M}=$ molecular weight markers. Samples were: (1) E. coli cell lysate; (2) soluble cell extract; (3) Talon ${ }^{\text {TM }}$ column pass through; (4) imidazole eluate from Talon ${ }^{\text {TM }}$ column; (5-7) peak fractions from Superdex S200 column; (8-15) peak fractions from MonoQ column.

Additional file 2: Figure S2. Specificity of the E. coli cytoplasmic trehalase (treF). Hydrolysis of trehalose, maltotriose and cellobiose by the E. coli cytoplasmic trehalase (treF) was determined by measuring the release of glucose in an end-point assay using glucose oxidase, peroxidase and Amplex Red ${ }^{\circledR}$. The increase in fluorescence is expressed in arbitrary fluorescence units. Data are mean \pm SD $(n=3)$.
\end{abstract}

\section{Abbreviations}

LC-MS/MS: Anion-exchange liquid chromatography-tandem mass spectrometry; TPP: Trehalose-phosphate phosphatase; TPS: Trehalose-phosphate synthase; Tre6P: Trehalose-6-phosphate.

\section{Competing interests}

The authors declare that they have no competing interests.

\section{Authors' contributions}

MS and $J$ conceived the study. PC, RF and YG developed the trehalose assay and carried out the measurements. NSN and DJ planned the maize ramosa3 mutant analysis and dissected the inflorescence primordia. OEB carried out the $A$. thaliana low temperature experiment. PC and $J$ drafted the manuscript and all authors approved the final manuscript.

\section{Acknowledgements}

Funding was provided by the Max Planck Gesellschaft (MS, YG, RF \& JL), the National Science Foundation - Plant Genome Program (DJ) and the National Research Initiative of the USDA Cooperative State Research, Education and Extension Service (DJ).

\section{Author details}

${ }^{1}$ Dipartimento di Scienze e Tecnologie Ambientali Biologiche e Farmaceutiche, Seconda Università degli Studi di Napoli, Via Vivaldi 43, I-81100, Caserta, Italy. ${ }^{2}$ Max Planck Institute of Molecular Plant Physiology, Am Mühlenberg 1, 14476, Potsdam-Golm, Germany. ${ }^{3}$ INRA Bordeaux, University of Bordeaux, UMR1332 Fruit Biology and Pathology, F-33883, Villenave d'Ornon, France. ${ }^{4}$ Cold Spring Harbor Laboratory, 1 Bungtown Road, Cold Spring Harbor, NY 11724, USA. ${ }^{5}$ Laboratory of Plant Genetics and Breeding, Department of Biological Production, Faculty of Bioresource Sciences, Kaidobata-nishi 241-438, Shimo-Shinjyo Nakano, Akita City 010-0195, Japan. ' Metanomics GmbH, Tegeler Weg 33, 10589, Berlin, Germany.

Received: 13 May 2013 Accepted: 13 June 2013

Published: 20 June 2013 


\section{References}

1. Augier J: The biochemistry of a North American algae, Tuomeyafluviatilis. Comptes Rendus 1954, 239:87-89.

2. Lindberg B: Studies on the chemistry of lichens. Investigation of a Dermatocarpon and some Roccella species. Acta Chem Scand 1955, 9:917-919.

3. Müller J, Boller T, Wiemken A: Trehalose and trehalase in plants: recent developments. Plant Sci 1995, 112:1-9.

4. Elbein AD, Pan YT, Pastuszak I, Carroll D: New insights on trehalose: a multifunctional molecule. Glycobiology 2003, 13(4):17R-27R.

5. Anselmino O, Gilg E: Über das Vorkommen von Trehalose in Selaginella lepidophylla. Berichte der Deutschen Pharmazeutischen Gesellschaft 1913, 23:326-330.

6. Iturriaga G, Gaff DF, Zentella R: New desiccation-tolerant plants, including a grass, in the central highlands of Mexico, accumulate trehalose. Aust J Bot 2000, 48:153-158.

7. Crowe JH, Carpenter JF, Crowe LM: The role of vitrification in anhydrobiosis. Annu Rev Physiol 1998, 60:73-103.

8. Oliver AE, Leprince O, Wolkers WF, Hincha DK, Heyer AG, Crowe JH: Non-disaccharide-based mechanisms of protection during drying. Cryobiology 2001, 43:151-167.

9. De Jesus PE, Dolly Panek A, Araujo Eleutherio EC: Protection against oxidation during dehydration of yeast. Cell Stress Chaperones 2003, 8:120-124.

10. Crowe JH, Hoekstra FA, Crowe LM: Anhydrobiosis. Annu Rev Physiol 1992, 54:579-599.

11. Avigad G: Accumulation of trehalose and sucrose in relation to the metabolism of alpha-glucosides in yeasts of defined genotype. Biochim Biophys Acta 1960, 40:124-134.

12. Blázquez MA, Santos E, Flores CL, Martínez-Zapater JM, Salinas J, Gancedo C: Isolation and molecular characterization of the Arabidopsis TPS1 gene, encoding trehalose-6-phosphate synthase. Plant J 1998, 13:685-689.

13. Vogel G, Fiehn O, Bressel LJRD, Boller T, Wiemken A, Aeschbacher RA, Wingler A: Trehalose metabolism in Arabidopsis: occurrence of trehalose and molecular cloning and characterization of trehalose-6-phosphate synthase homologues. J Exp Bot 2001, 52:1817-1826.

14. Avonce N, Mendoza-Vargas A, Morett E, Iturriaga G: Insights on the evolution of trehalose biosynthesis. BMC Evol Biol 2006, 6(109):1-15.

15. Cabib E, Leloir LF: The biosynthesis of trehalose phosphate. J Biol Chem 1958, 231:259-275

16. Leyman B, Van Dijck P, Thevelein JM: An unexpected plethora of trehalose biosynthesis genes in Arabidopsis thaliana. Trends Plant Sci 2001, 6:510-513.

17. Vandesteene L, Ramon M, Le Roy K, Van Dijck P, Rolland F: A single active trehalose-6-P synthase (TPS) and a family of putative regulatory TPS-like proteins in Arabidopsis. Mol Plant 2010, 3:406-419.

18. Vandesteene L, López-Galvis L, Vanneste K, Feil R, Lammens W, Rolland F, Lunn JE, Avonce N, Beeckman T, Van Dijck P: Expansive evolution of the TREHALOSE-6-PHOSPHATE PHOSPHATASE gene family in Arabidopsis thaliana. Plant Physiol 2012, 160:884-896.

19. Frison M, Parrou JL, Guillaumot D, Masquelier D, François J, Chaumont F, Batoko H: The Arabidopsis thaliana trehalase is a plasma membranebound enzyme with extracellular activity. FEBS Lett 2007, 581:4010-4016.

20. Lunn JE: Gene families and evolution of trehalose metabolism in plants. Funct Plant Biol 2007, 34:550-563.

21. Eastmond PJ, Van Dijken AJ, Spielman M, Kerr A, Tissier AF, Dickinson HG, Jones JD, Smeekens SC, Graham IA: Trehalose-6-phosphate synthase 1, which catalyses the first step in trehalose synthesis, is essential for Arabidopsis embryo maturation. Plant J 2002, 29:225-235.

22. Van Dijken AJH, Schluepmann H, Smeekens SCM: Arabidopsis trehalose-6phosphate synthase 1 is essential for normal vegetative growth and transition to flowering. Plant Physiol 2004, 135:969-977.

23. Gómez LD, Gildaz A, Feil R, Lunn JE, Graham IA: AtTPS1 mediated trehalose-6-phosphate synthesis is essential for embryogenic and vegetative growth and responsiveness to $A B A$ in germinating seeds and stomatal guard cells. Plant J 2010, 64:1-13.

24. Schluepmann H, Pellny T, Van Dijken A, Smeekens S, Paul MJ: Trehalose 6-phosphate is indispensable for carbohydrate utilisation and growth in Arabidopsis thaliana. Proc Natl Acad Sci U S A 2003, 100:6849-6854.

25. Zhang Y, Primavesi LF, Jhurreea D, Andralojc PJ, Mitchell RAC, Powers SJ, Schluepmann H, Delatte T, Wingler A, Paul MJ: Inhibition of SNF1-related protein kinase 1 activity and regulation of metabolic pathways by trehalose-6-phosphate. Plant Physiol 2009, 149:1860-1871.
26. Geigenberger $\mathrm{P}$ : Regulation of starch biosynthesis in response to a fluctuating environment. Plant Physiol 2011, 155:1566-1577.

27. Paul M, Van Dijck P: How do sugars regulate plant growth? A commentary on Trehalose 6-phosphate: connecting plant metabolism and development by Ponnu J, Wahl V, Schmid M. Front. Front Plant Sci 2011, 2:90.

28. Ponnu J, Wahl V, Schmid M: Trehalose 6-phosphate: connecting plant metabolism and development. Front Plant Sci 2011, 2:70. http://www. frontiersin.org/Plant_Physiology/10.3389/fpls.2011.00070/full.

29. O'Hara LE, Paul MJ, Wingler A: How do sugars regulate plant growth and development? new insight into the role of trehalose-6-phosphate. Mol Plant 2013, 6:261-274. http://mplant.oxfordjournals.org/content/6/2/261.long.

30. Schluepmann H, Berke L, Sanchez-Perez GF: Metabolism control over growth: a case for trehalose-6-phosphate in plants. J Exp Bot 2012 63:3379-3390

31. Wahl V, Ponnu J, Schlereth A, Arrivault S, Langenecker T, Franke A, Feil R Lunn JE, Stitt M, Schmid M: Regulation of flowering by trehalose6-phosphate signaling in Arabidopsis thaliana. Science 2013, 339:704-707.

32. Lunn JE, Feil R, Hendriks JHM, Gibon Y, Morcuende R, Osuna D, Scheible W-R, Carillo P, Hajirezaei M-R, Stitt M: Sugar-induced increases in trehalose 6-phosphate are correlated with redox activation of ADPglucose pryophosphorylase and higher rates of starch synthesis in Arabidopsis thaliana. Biochem J 2006, 397:139-148.

33. Fernandez O, Béthencourt L, Quero A, Sangwan RS, Clément C: Trehalose and plant stress responses: friend or foe? Trends Plant Sci 2010, 15:409-417.

34. Djonović S, Urbach JM, Drenkard E, Bush J, Feinbaum R, Ausubel JL, Traficante D, Risech M, Kocks C, Fischbach MA, Priebe GP, Ausubel FM: Trehalose biosynthesis promotes Pseudomonas aeruginosa pathogenicity in plants. PLoS Pathog 2013, 9(3):e1003217. http://www. plospathogens.org/article/info\%3Adoi\%2F10.1371\%2Fjournal.ppat.1003217. Epub 2013 Mar 7.

35. Wilson RA, Jenkinson JM, Gibson RP, Littlechild JA, Wang ZY, Talbot NJ: Tps1 regulates the pentose phosphate pathway, nitrogen metabolism and fungal virulence. EMBO J 2007, 26:3673-3685

36. Gravot A, Grillet L, Wagner G, Jubault M, Lariagon C, Baron C, Deleu C, Delourme R, Bouchereau A, Manzanares-Dauleux MJ: Genetic and physiological analysis of the relationship between partial resistance to clubroot and tolerance to trehalose in Arabidopsis thaliana. New Phytol 2011, 191:1083-1094.

37. Brodmann D, Schuller A, Ludwig-Müller J, Aeschbacher RA, Wiemken A, Boller T, Wingler A: Induction of trehalase in Arabidopsis plants infected with the trehalose-producing pathogen Plasmodiophora brassicae. Mol Plant Microbe Interact 2002, 15:693-700.

38. Bae H, Herman E, Bailey B, Bae H-J, Sicher R: Exogenous trehalose alters Arabidopsis transcripts involved in cell wall modification, abiotic stress, nitrogen metabolism, and plant defense. Physiol Plant 2005, 125:114-126.

39. Aghdasi M, Smeekens S, Schluepman H: Microarray analysis of gene expression patterns in Arabidopsis seedlings under trehalose, sucrose and sorbitol treatment. Int J Plant Prod 2008, 2:309-320.

40. Reignault P, Cogan A, Muchembled J, Sahraoui ALH, Durand R, Sancholle M: Trehalose induces resistance to powdery mildew in wheat. New Phytol 2001, 149:519-529.

41. Renard-Merlier D, Randoux B, Nowak E, Farcy F, Durnad R, Reignault P: lodus 40 , salicylic acid, heptanoyl salicylic acid and trehalose exhibit different efficacies and defense targets during wheat/powdery mildew infection. Phytochemistry 2007, 68:1156-1164.

42. Aeschbacher RA, Müller J, Boller T, Wiemken A: Purification of the trehalase GMTRE1 from soybean nodules and cloning of its CDNA. GMTRE 1 is expressed at a low level in multiple tissues. Plant Physiol 1999, 119:489-495.

43. Suárez R, Wong A, Ramiréz M, Barraza A, Orozco MC, Cevallos MA, Lara M, Hernandéz G, Iturriaga G: Improvement of drought tolerance and grain yield in comon bean by overexpressing trehalose-6-phosphate synthase in rhizobia. Mol Plant Microbe Interact 2008, 21:958-966.

44. López M, Herrera-Cervera JA, Iribarne C, Tejera NA, Lluch C: Growth and nitrogen fixation in Lotus japonicus and Medicago truncatula under $\mathrm{NaCl}$ stress: nodule carbon metabolism. J Plant Physiol 2008, 165:641-650.

45. López M, Tejera NA, Iribarne C, Lluch C, Herrera-Cervera JA: Trehalose and trehalase in root nodules of Medicago truncatula and Phaseolus vulgaris in response to salt stress. Physiol Plant 2008, 134:575-582.

46. López M, Tejera NA, Lluch C: Validamycin A improves the response of Medicago truncatula plants to salt stress by inducing trehalose accumulation in the root nodules. Plant Physiol 2009, 166:1218-1222. 
47. Domínguez-Ferreras A, Soto MJ, Pérez-Arnedo R, Olivares J, Sanjuán J: Importance of trehalose biosynthesis for sinorhizobium meliloti osmotolerance and nodulation of alfalfa roots. J Bacterio/ 2009, 191:7490-7499.

48. Brechenmacher L, Lei Z, Libault M, Findley S, Sugawara M, Sadowsky MJ Lloyd W, Sumner LW, Stacey G: Soybean metabolites regulated in root hairs in response to the symbiotic bacterium Bradyrhizobium japonicum. Plant Physiol 2010, 153:1808-1822.

49. López MF, Männer P, Willmann A, Hampp R, Nehls U: Increased trehalose biosynthesis in Hartig net hyphae of ectomycorrhizas. New Phytol 2007, 174:389-398.

50. Corrêa A, Hampp R, Magel E, Loução M: Carbon allocation in ectomycorrhizal plants at limited and optimal $\mathrm{N}$ supply: an attempt at unraveling conflicting theories. Mycorrhiza 2010, 21:35-51.

51. Nehls U, Göhringer F, Wittulsky S, Dietz S: Fungal carbohydrate support in the ectomycorrhizal symbiosis: a review. Plant Biology 2010, 12:292-301.

52. Fernandez $\mathrm{O}$, Vandesteene L, Feil R, Baillieul F, Lunn JE, Clément C: Trehalose metabolism is activated upon chilling in grapevine and might participate in Burkholderia phytofirmans induced chilling tolerance. Planta 2012, 236:355-369.

53. Rodríguez-Salazar J, Suárez R, Caballero-Mellado J, Iturriaga G: Trehalose accumulation in Azospirillum brasilense improves drought tolerance and biomass in maize plants. FEMS Microbiol Lett 2009, 296:52-59.

54. Iordachescu M, Imai R: Trehalose biosynthesis in response to abiotic Stresses. J Integr Plant Biol 2008, 50:1223-1229.

55. Pramanik $\mathrm{MH}$, Imai R: Functional identification of a trehalose 6-phosphate phosphatase gene that is involved in transient induction of trehalose biosynthesis during chilling stress in rice. Plant Mol Biol 2005, 58:751-762.

56. Ge LF, Chao DY, Shi M, Zhu MZ, Gao JP, Lin HX: Overexpression of the trehalose-6-phosphate phosphatase gene OsTPP1 confers stress tolerance in rice and results in the activation of stress responsive genes. Planta 2008, 228:191-201.

57. Su CF, Wang YC, Hsieh TH, Lu CA, Tseng TH, Yu SM: A novel MYBS3dependent pathway confers cold tolerance in rice. Plant Physiol 2010, 153:145-158.

58. Goddijn OJ, Verwoerd TC, Voogd E, Krutwagen RW, De Graaf PT, Van Dun K, Poels J, Ponstein AS, Damm B, Pen J: Inhibition of trehalase activity enhances trehalose accumulation in transgenic plants. Plant Physiol 1997, 113:181-190.

59. Romero C, Bellés JM, Vayá JL, Serrano R, Culiáñez-Macià FA: Expression of the yeast trehalose-6-phosphate synthase gene in transgenic tobacco plants: pleiotropic phenotypes include drought tolerance. Planta 1997, 201:293-297.

60. Pilon-Smits EAH, Terry N, Sears T, Kim H, Zayed A, Hwang S, Van Dun K, Voogd E, Verwoerd TC, Krutwagen RWHH, Goddijn OJM: Trehaloseproducing transgenic tobacco plants show improved growth performance under drought stress. J Plant Physiol 1998, 152:525-532.

61. Cortina C, Culiáñez-Macià FA: Tomato abiotic stress enhanced tolerance by trehalose biosynthesis. Plant Sci 2005, 169:75-82

62. Wingler A, Delatte TL, O'Hara LE, Primavesi LF, Jhurreea D, Paul MJ, Schluepmann H: Trehalose 6-phosphate is required for the onset of leaf senescence associated with high carbon availability. Plant Physiol 2012, 158:1241-1251.

63. Garg AK, Kim JK, Owens TG, Ranwala AP, Choi YD, Kochian LV, Wu RJ: Trehalose accumulation in rice plants confers high tolerance levels to different abiotic stresses. PNAS 2002, 99:15898-15903.

64. Jang IC, Oh SJ, Seo JS, Choi WB, Song SI, Kim CH, Kim YS, Seo HS, Choi YD, $\mathrm{Nahm} \mathrm{BH,} \mathrm{Kim} \mathrm{JK:} \mathrm{Expression} \mathrm{of} \mathrm{a} \mathrm{bifunctional} \mathrm{fusion} \mathrm{of} \mathrm{the} \mathrm{Escherichia}$ coli genes for trehalose-6-phosphate synthase and trehalose6-phosphate phosphatase in transgenic rice plants increases trehalose accumulation and abiotic stress tolerance without stunting growth. Plant Physiol 2003, 131:516-524.

65. Miranda JA, Avonce N, Suárez R, Thevelein JM, Van Dijck P, Iturriaga G: A bifunctional TPS-TPP enzyme from yeast confers tolerance to multiple and extreme abiotic-stress conditions in transgenic Arabidopsis. Planta 2007, 226:1411-1421.

66. Lee S-B, Kwon H-B, Kwon S-J, Park S-C, Jeong M-J, Han S-E, Byun M-O, Daniell $\mathrm{H}$ : Accumulation of trehalose within transgenic chloroplasts confers drought tolerance. Mol Breed 2003, 11:1-13.

67. Penna S: Building stress tolerance through over-producing trehalose in transgenic plants. Trends Plant Sci 2003, 8:355-357.
68. Karim $\mathrm{S}$, Aronsson $\mathrm{H}$, Ericson $\mathrm{H}$, Pirhonen $\mathrm{M}$, Leyman $\mathrm{B}$, Welin $\mathrm{B}$, Mäntylä $\mathrm{E}$, Palva ET, Van Dijck P, Holmström KO: Improved drought tolerance without undesired side effects in transgenic plants producing trehalose. Plant Mol Biol 2007, 64:371-386.

69. Müller J, Wiemken A, Aeschbacher R: Trehalose metabolism in sugar sensing and plant development. Plant Sci 1999, 147:37-47.

70. Van Houtte H, Vandesteene L, López-Galvis L, Lemmens L, Kissel E, Carpentier S, Feil R, Avonce N, Beeckman T, Lunn JE, Van Dijck P: Overexpression of the trehalase gene AtTRE1 leads to increased drought stress tolerance in Arabidopsis and is involved in ABA-induced stomatal closure. Plant Physiol 2013, 161:1158-1171.

71. Li HW, Zang BS, Deng XW, Wang XP: Overexpression of the trehalose6-phosphate synthase gene OsTPS1 enhances abiotic stress tolerance in rice. Planta 2011, 234:1007-1018.

72. Schluepmann H, Van Dijken A, Aghdasi M, Paul M, Smeekens S: Trehalose mediated growth inhibition of Arabidopsis seedlings is due to trehalose6-phosphate accumulation. Plant Physiol 2004, 135:879-890.

73. Ramon M, Rolland F, Thevelein JM, Van Dijck P, Leyman B: ABI4 mediates the effects of exogenous trehalose on Arabidopsis growth and starch breakdown. Plant Mol Biol 2007, 63:195-206.

74. Satoh-Nagasawa N, Nagasawa N, Malcomber S, Sakai H, Jackson D: A trehalose metabolic enzyme controls inflorescence architecture in maize. Nature 2006, 441:227-230.

75. Kandler $\mathrm{O}, \mathrm{Hopf} \mathrm{H}$ : Occurrence, metabolism and function of oligosaccharides. In The Biochemistry of Plants, Volume 3, Carbohydrates: structure and function. Edited by Preiss J. Accademic Press; 1980:220-270.

76. Avigad G: Sucrose and other disaccharides. In Encyclopedia of Plant Physiology, Volume 13A, Plant Carbohydrates - I Intracellular carbohydrates. Edited by Loewus FA, Tanner W. Verlag: Springer; 1982:271-276.

77. Oesch F, Meier H: Trehalose in the cambial sap of Fagus silvatica L. Phytochemistry 1967, 6:1147-1148.

78. Elbein AD: The metabolism of alpha, alpha-trehalose. Adv Carbohydr Chem Biochem 1974, 30:227-256

79. Streeter JG, Bosler ME: Carbohydrates in soybean nodules: identification of compounds and possible relationships to nitrogen fixation. Plant Sci Lett 1976, 7:321-329.

80. Deslauriers $\mathrm{R}$, Jarrell HC, Byrd RA, Smith IC: Observation by ${ }^{13} \mathrm{C}$ NMR of metabolites in differentiating amoeba. Trehalose storage in encysted Acanthamoeba castellanii. FEBS Lett 1980, 118:185-190.

81. Hanko VP, Rohrer JS: Determination of carbohydrates, sugar alcohols, and glycols in cell cultures and fermentation broths using high-performance anion-exchange chromatography with pulsed amperometric detection. Anal Biochem 2000, 283:192-199.

82. Vázquez-Ortiz FA, Valenzuela-Soto EM: HPLC Determination of Trehalose in Selaginella lepidophylla plants. J Liq Chromatogr Relat Technol 2004, 27:1947-1953.

83. Quéro A, Béthencourt L, Pilard S, Fournet A, Guillot X, Sangwan RS, BoitelConti $M$, Courtois J, Petit E: Trehalose determination in linseed subjected to osmotic stress. HPAEC-PAD analysis: an inappropriate method. Physiol Plant 2013, 147:261-269.

84. Roessner U, Wagner C, Kopka J, Trethewey RN, Willmitzer L: Simultaneous analysis of metabolites in potato tuber by gas chromatography-mass spectrometry. Plant J 2000, 23:131-142.

85. Parrou $J$, Francois J: A simplified procedure for a rapid and reliable assay of both glycogen and trehalose in whole yeast cells. Anal Biochem 1997, 248:186-188.

86. Hädrich N, Hendriks JHM, Kötting O, Arrivault S, Feil R, Zeeman SC, Gibon Y, Schulze W, Stitt M, Lunn JE: Mutagenesis of cysteine 81 prevents dimerization of the APS1 subunit of ADP-glucose pyrophosphorylase and alters diurnal starch turnover in Arabidopsis thaliana leaves. Plant J 2011, 70:231-242.

87. Pal SK, Liput M, Piques M, Ishihara H, Martins MCM, Sulpice R, Van Dongen JT, Yadav UP, Lunn JE, Usadel B, Schulze WX, Stitt M: Diurnal changes of polysome loading track sucrose content in the rosette of wildtype Arabidopsis and the starchless pgm mutant. Plant Physiol 2013. pp.112.212258; First Published on May 14, 2013; doi:10.1104/pp.112.212258.

88. Horlacher R, Uhland K, Klein W, Boos EM: Characterization of a cytoplasmic trehalase of Escerichia coli. J Bacteriol 1996, 178:6250-6257.

89. Gibon Y, Pyl ET, Sulpice R, Lunn JE, Höhne M, Günther M, Stitt M: Adjustment of growth, starch turnover, protein content and central metabolism to a decrease of the carbon supply when Arabidopsis is grown in very short photoperiods. Plant Cell Environ 2009, 32:859-874. 
90. Stitt M, Hurry V: A plant for all seasons: alterations in photosynthetic carbon metabolism during cold acclimation in Arabidopsis. Curr Opin Plant Biol 2002, 5:199-206.

91. Van Dijck P, Mascorro-Gallardo JO, De Bus M, Royackers K, Iturriaga G, Thevelein JM: Truncation of Arabidopsis thaliana and Selaginella lepidophylla trehalose-6-phosphate synthase unlocks high catalytic activity and supports high trehalose levels on expression in yeast. Biochem J 2002, 366:63-71.

92. Caspar T, Huber SC, Somerville C: Alterations in growth, photosynthesis, and respiration in a starchless mutant of Arabidopsis thaliana (L.) deficient in chloroplast phosphoglucomutase activity. Plant Physiol 1985, 79:11-17.

93. Stitt M, McLilley R, Gerhardt R, Heldt HW: Metabolite levels in specific cells and subcellular compartments of plant leaves. Methods Enzymol 1989, 174:518-552.

doi:10.1186/1746-4811-9-21

Cite this article as: Carillo et al: A fluorometric assay for trehalose in the picomole range. Plant Methods 2013 9:21.

\section{Submit your next manuscript to BioMed Central and take full advantage of:}

- Convenient online submission

- Thorough peer review

- No space constraints or color figure charges

- Immediate publication on acceptance

- Inclusion in PubMed, CAS, Scopus and Google Scholar

- Research which is freely available for redistribution 